Kết quả nghiên cứu của chúng tôi cũng phù hợp kết quả nghiên cứu của Puri và CS[5] với tỷ lệ biến chứng chung là $3,6 \%$ hay trong nghiên cứu của Yoshikawa và CS [8] cho thây tỷ lệ biến chứng là $2,8 \%$.

\section{KẾT LUẬN}

Phẫu thuật nội soi lồng ngực điều trị tràn khí màng phổi tự phát nguyên phát là phương pháp an toàn và hiệu quả, với thời gian điều trị ngắn, khả năng phục hồi nhanh, tỷ lệ tai biến, biến chứng thấp.

\section{TÀI LIÊU THAM KHẢO}

1. Hallifax Rob J, Goldacre Raph, Landray Martin J, et al. (2018), "Trends in the incidence and recurrence of inpatient-treated spontaneous pneumothorax, 1968-2016", Jama, 320(14), 1471-1480.

2. Olesen Winnie Hedevang, Titlestad Ingrid Louise, Andersen Poul Erik, et al. (2019), "Incidence of primary spontaneous pneumothorax: a validated, register-based nationwide study", ERJ open research, 5(2), 00022-2019.

3. MacDuff Andrew, Arnold Anthony, Harvey John (2010), "Management of spontaneous pneumothorax: British Thoracic Society pleural disease guideline 2010", Thorax, 65(Suppl 2), ii18-ii31.

4. Doğusoy Ilgaz, Yıldırım Mehmet, Ustaalioğlu Recep, et al. (2018), "A comparison of axillary thoracotomy versus video-assisted thoracoscopic surgery in the surgical treatment of primary spontaneous pneumothorax", Turk gogus kalp damar cerrahisi dergisi, 26(1), 132-137.

5. Puri Harsh Vardhan, Asaf Belal Bin, Pulle Mohan Venkatesh, et al. (2021), "Video-assisted thoracoscopic surgery management of primary spontaneous pneumothorax: Results in 110 consecutive cases", Lung India : official organ of Indian Chest Society, 38(1), 36-40.

6. Aljehani Yasser Mahir, Almajid Feras Mohammed, Niaz Rabia C., et al. (2018), "Management of Primary Spontaneous Pneumothorax: A Single-center Experience", Saudi journal of medicine \& medical sciences, 6(2), 100-103.

7. Chikaishi Yasuhiro, Kanayama Masatoshi, Taira Akihiro, et al. (2019), "What is the best treatment strategy for primary spontaneous pneumothorax? A retrospective study", Annals of medicine and surgery (2012), 45, 98-101.

8. Yoshikawa Ryohei, Matsuura Natsumi, Igai Hitoshi, et al. (2021), "Uniportal approach as an alternative to the three-portal approach to videoassisted thoracic surgery for primary spontaneous pneumothorax", Journal of thoracic disease, 13(2), 927-934.

\title{
NGHIÊN CỨU GIẢI PHẪU ĐÔ̂NG MACH CHẬU TRONG TRÊN HÌNH ẢNH CHỤP CẮT LỚP VI TÍNH 128 LỚP
}

\section{TÓM TẮT}

Mục tiêu: Xác định nguyên ủy, kích thước và phân nhánh động mạch chậu trong trên hình ảnh chụp cắt lớp vi tính 128 lớp và phân tích ý nghĩa lâm sàng trong các trường hợp biến đổi giải phẫu động mạch. Phương pháp nghiên cứu: Mố tả tiến cứu và mồ tả hồi cứu từ 9/2017 đến 9/2018. Chọn mẫu: 128 tệp ảnh của 128 bệnh nhân với tiêu chuẩn lựa chọn là hình ảnh chụp động mạch chậu rõ nét và các tổn thương hẹp, tắc không quá $50 \%$ đường kính lòng động mạch. Kết quả $100 \%$ động mạch chậu trong được quan sát trên các tệp ảnh, 127 trường hợp quan sát thấy thân trước, thân sau đat $100 \%$, các nhánh mạch chỉ quan sát được từ $62 \%$ đến $100 \%$. Đường kính động mach chậu và thân chính là khoảng $3 \mathrm{~mm}$, các nhánh có đường kính nhỏ hơn $2 \mathrm{~mm}$. Các nhánh mach có tỷ lê biến đổi vị trí nguyên ủy từ $0.78 \%$ đến $6.82 \%$. Kết luận: Chụp cắt lớp vi tính 128 lớp là

\footnotetext{
${ }^{1}$ Trường Đai hoc Y Dước Thái Bình

Chịu trách nhiệm chính: Vũ Duy Tùng

Email: tunganatomy@gmail.com

Ngày nhận bài: 22/4/2021

Ngày phản biên khoa hoc: 19/5/2021

Ngày duyệt bài: 12/6/2021
}

Vũ Duy Tùng ${ }^{1}$, Nguyễn Thị Tho' ${ }^{1}$, Trần Thị Hằng ${ }^{1}$, Nguyễn Ngọc Trung ${ }^{1}$

phương tiên có khả năng thể hiện chính xác kích thước, hình thái và các biến đổi giải phấu động mạch.

Tư khóa: Giải phẫu động mạch chậu trong

\section{SUMMARY \\ ANATOMICAL RESEARCH OF ILIAC ARTERY ON THE IMAGE 128 MULTI SLICE COMPUTED TOMOGRAPHY}

Objective: Determination of the arises, size and branching of the pelvic arteries in the image on computed tomography of 128 grade and the analysis of clinical significance in cases of arterial anatomical changes. Research methods: Descriptive studies and retrospective studies from 9/2017 to 9/2018. Select Sample: 128 photo-files of 128 patients with the standard of choice are clear pelvic artery imaging and narrow lesions, which are not exceeding $50 \%$ of the arterial diameter. Results $100 \%$ of the pelvic artery is observed on the image files, 127 cases observed hull first, rear fuselage reached $100 \%$, the vascular branches were observed only from $62 \%$ to $100 \%$. The pelvic artery diameter and the main body are about $3 \mathrm{~mm}$, the branches are smaller in diameter than $2 \mathrm{~mm}$. The circuit branches have a arises variation ratio of $0.78 \%$ to $6.82 \%$. Conclusion: Computed tomography 128 grade is the means capable of 
accurately showing the size, morphology and arterial anatomical changes.

Keywords: Anatomy of the iliac artery

\section{I. ĐĂT VẤN ĐỀ}

Giải phẫu động mạch chậu trong (ĐMCT) ngày càng được quan tâm đặc biệt trong nút mạch điều trị bệnh lý các tạng vùng chậu. Trong thủ thuật nút mạch để kiểm soát tình trạng chảy máu nghiêm trọng tại bàng quang, tuyến tiền liệt, trực tràng, tầng sinh môn sau chấn thương hay sau sinh thiết, thì giải phẫu ĐM vùng chậu là không thể bỏ sót [1],[2]. Việc đánh giá động mạch chậu trong bằng phương pháp nghiên cứu kinh điển như phẫu tích, làm khuôn đúc động mạch gặp rất nhiều khó khăn, do vùng này nằm trong khung chậu hẹp, có nhiều tổ chức liên kết [8]. Trong khi đó, ngày nay với sự ra đời của các kỹ thuật mới như chụp cắt lớp vi tính 128 lớp, chụp mạch qua da đều có khả năng khảo sát các mạch máu với độ chính xác cao. Nắm vững về đường đi, kích thước từng đoạn và các biến đổi giải phẫu của ĐMCT là cơ sở quan trọng cho bác sĩ lâm sàng phiên giải (đọc) các phim chụp mạch, đo kích thước trên siêu âm, phẫu thuật hay thực hiện các thủ thuật can thiệp mạch máu một cách đúng đắn và chính xác nhằm nâng cao hiệu quả điều trị. Vì vậy chúng tôi tiến hành đề tài với mục tiêu:

- Xác định nguyên ửy, kích thước và phân nhánh động mạch chậu trong trên hình ảnh chụp cắt lớp vi tính 128 lớp

- Phân tích ý nghĩa lâm sàng trong các trường hợp biến đổi giải phẫu động mạch

\section{II. ĐỐI TƯỢNG VÀ PHƯƠNG PHÁP NGHIÊN CỨU}

2.1. Phương pháp nghiên cứu. Nghiên cứu được tiến hành theo phương pháp mô tả.

\section{2. Đối tượng nghiên cứu}

- Tiêu chuẩn lựa chọn: Gồm 128 tệp ảnh của 128 bệnh nhân chụp cắt lớp vi tính 128 lớp vùng bụng chậu tại khoa chẩn đoán hình ảnh Bênh viện Đa khoa Thái Bình từ tháng 9/2017 đến hết tháng 9/2018 có hình ảnh chụp động mạch chậu rõ nét, tổn thương hẹp, tắc không quá $50 \%$ đường kính lòng động mạch.

- Tiêu chuẩn loại trừ: Các bệnh nhân không đạt tiêu chuẩn trên và những bệnh nhân có hình ảnh nhiễu hay hình ảnh động mạch chậu bệnh lý.

2.3. Cỡ mẫu. Lấy mẫu thuân tiện với các bệnh nhân chụp chậu bụng trong thời gian nghiên cứu có tiêu chuẩn phù hợp.

\subsection{Kỹ thuật chụp}

- Vị trí thăm khám là dưới chỗ phân chia động mạch chậu chung đến hết sàn chậu

- Thuốc cản quang Nonionic hay Ultravist $300 \mathrm{mg} / 100 \mathrm{ml}$

- Tốc độ tiêm $3 \mathrm{ml} / \mathrm{s}$

- Độ dầy lát cắt 0,625 mm

- Thời gian mỗi vòng quay $0,35 \mathrm{~s}$

- Dựng hình MIP và 3D

\section{KẾT QUẢ NGHIÊN CứU}

\section{1. Đặc điểm động mạch chậu trong theo tuổi, giới}

Bảng 3.1. Đặc điểm động mạch chậu trong theo tuổi, giới

\begin{tabular}{|c|c|c|c|c|c|}
\hline \multirow{2}{*}{ Tuổi Giới } & \multicolumn{2}{|c|}{ ĐM chậu ở nam } & \multicolumn{2}{|c|}{ ĐM chậu ở nữ } & \multirow{2}{*}{ Tổng } \\
\hline & $\mathbf{n}$ & Tỷ lệ \% & $\mathbf{n}$ & Tỷ lệ \% & \\
\hline$\leq 18$ & 02 & 2,85 & 02 & 3,44 & 04 \\
\hline $19-60$ & 42 & 60,0 & 25 & 43,0 & 67 \\
\hline$>60$ & 26 & 37,15 & 31 & 53,56 & 57 \\
\hline Tống & 70 & 100 & 58 & 100 & 128 \\
\hline
\end{tabular}

Nhận xét: Tỷ lệ chung giữa nam và nữ là tương đương nhau. Nam giới từ 19 tuối đến 60 tuối đạt $60 \%$, nhóm nam giới trên 60 tuổi thấp hơn 37\%, ngược lại nhóm bệnh nhân nữ trên 60 tuổi đạt 53,56\%, từ 19 đến 60 tuổi chiếm 43\%. Nhóm bệnh nhân ở độ tuổi dưới 19 tuổi là không đáng kể ở cả hai giới với tỷ lệ khoảng 2,85\% tới 3,44\%.

\section{2. Đường kính ĐM chậu trong}

Bảng 3.2. Đường kính động mạch chậu trong

\begin{tabular}{|c|c|c|c|c|}
\hline \multirow{2}{*}{ Động mạch Đường kính } & \multirow{2}{*}{$\mathbf{n}$} & \multirow{2}{*}{$\overline{\mathrm{X}} \pm$ SD (mm) } & \multicolumn{2}{|c|}{ Phân bố } \\
\hline & & & Max (mm) & Min (mm) \\
\hline Động mạch chậu trong & 128 & $3,401 \pm 0,305$ & 4,2 & 2,3 \\
\hline Thân trước & 127 & $2,07 \pm 0,16$ & 2,9 & 1,6 \\
\hline Thân sau & 128 & $3,5 \pm 0,2$ & 4,2 & 2,4 \\
\hline Động mạch bịt & 115 & $1,8 \pm 0,1$ & 2,2 & 1,3 \\
\hline Đông mach then trong & 116 & $0,8 \pm 0,05$ & 1,3 & 0,5 \\
\hline ĐM mông trên & 128 & $1,4 \pm 0,1$ & 2,0 & 0,8 \\
\hline
\end{tabular}


Nhận xét: Các nhánh mạch được tách ra từ động mạch chậu trong đều có đường kính nhỏ thua $4 \mathrm{~mm}$, đường kính thân sau 3,5mm, động mạch bịt và động mạch mông trên có đường kính từ 1,5 $2 \mathrm{~mm}$. Các nhánh tách ra từ các nhánh bên đều có đường kính nhỏ hơn $1 \mathrm{~mm}$.

\section{3. Đường kính các nhánh ĐM châuu trong theo giới}

Bảng 3.3. Đường kính các nhánh Đ̈M chậu trong theo giới

\begin{tabular}{|c|c|c|c|c|c|c|c|c|c|}
\hline \multirow{2}{*}{$\begin{array}{l}\text { Nhánh Giới } \\
\text { mạch }\end{array}$} & \multicolumn{4}{|c|}{ Nam } & \multicolumn{4}{|c|}{ Nữ } & \multirow[b]{2}{*}{ p } \\
\hline & $\mathbf{n}$ & $\begin{array}{r}\bar{X} \begin{array}{c} \pm \text { SD } \\
(\mathbf{m m})\end{array} \\
\end{array}$ & $\begin{array}{c}\text { Max } \\
(\mathrm{mm})\end{array}$ & $\begin{array}{c}\text { Min } \\
(\mathbf{m m})\end{array}$ & n & $\begin{array}{cc} \pm \text { SD } \\
\bar{X} & (\mathbf{m m}) \\
\end{array}$ & $\begin{array}{c}\text { Max } \\
(\mathrm{mm})\end{array}$ & $\begin{array}{c}\text { Min } \\
(\mathrm{mm})\end{array}$ & \\
\hline ĐMC trong & 70 & $3,44 \pm 0,18$ & 4,2 & 2,5 & 58 & $3,48 \pm 0,28$ & 4,2 & 2,3 & 0,7 \\
\hline Thân trước & 69 & $2,06 \pm 0,19$ & 2,5 & 1,6 & 58 & $2,07 \pm 0,14$ & 2,9 & 1,4 & 0,8 \\
\hline Thân sau & 70 & $3,6 \pm 0,09$ & 4,2 & 2,9 & 58 & $3,46 \pm 0,25$ & 4,2 & 2,4 & 0,1 \\
\hline ĐM bịt & 63 & $1,86 \pm 0,06$ & 2,2 & 1,3 & 52 & $1,78 \pm 0,05$ & 2,2 & 1,3 & 0,1 \\
\hline ĐM thẹn & 65 & $0,83 \pm 0,02$ & 1,2 & 0,5 & 51 & $0,82 \pm 0,03$ & 1,3 & 0,6 & 0,8 \\
\hline ĐM tử cung & 0 & 0 & 0 & 0 & 44 & $1,2 \pm 0,1$ & 2,0 & 0,6 & \\
\hline ĐM TLT & 52 & $0,8 \pm 0,02$ & 1,2 & 0,4 & 0 & 0 & 0 & 0 & \\
\hline ĐM mông trêr & 70 & $1,4 \pm 0,07$ & 2,0 & 0,9 & 58 & $13 \pm 0.06$ & 1,8 & 0.8 & 0.1 \\
\hline
\end{tabular}

Nhận xét: Đường kính động mạch chậu trong có đường kính 3,44 $\pm 0,18 \mathrm{~mm}$ ở nam giới, kích thước này cũng tương đồng với nữ là $3,48 \pm 0,28 \mathrm{~mm}$. Các nhánh mạch còn lại của động mạch chậu trong đều có đường kính tương đương giữa hai giới và nhỏ hơn $2 \mathrm{~mm}$.

3.4. Các biến đổi nguyên ủy động mạch mông trên

Bảng 3.4. Các dạng biến đổi nguyên ửy động mạch mông trên

\begin{tabular}{|c|c|c|}
\hline \multirow{2}{*}{ Từ ĐM Nguyên ủy } & \multicolumn{3}{|c|}{ Dộng mạch mông trên } \\
\cline { 2 - 3 } & $\mathbf{n}$ & Tỹ lệ $\%$ \\
\hline Thân sau & 120 & 93,76 \\
\hline ĐM chậu & 1 & 0,78 \\
\hline Mông dưới & 5 & 3,9 \\
\hline ĐM sinh dục & 1 & 0,78 \\
\hline ĐM bịt & 1 & 0,78 \\
\hline Tống & $\mathbf{1 2 8}$ & $\mathbf{1 0 0}$ \\
\hline
\end{tabular}

Nhận xét: Động mạch mông trên đa phần được tách ra từ thân sau với 93,76\%, 3,9\% động mach mông trên được tách cùng động mạch mồng dưới, động mạch mông trên có thể được tách ra từ động mạch sinh dục, động mạch bịt tách trực tiếp từ động mạch chậu với tỷ lệ 0,78\%.

3.5. Các biến đổi nguyên ủy động mạch mông dưới

Bảng 3.5. Các dạng biến đổi nguyên ửy động mạch mông dưới

\begin{tabular}{|c|c|c|}
\hline \multirow{2}{*}{ Từ ĐM Nguyên ủy } & \multicolumn{3}{|c|}{ Động mạch mông dưới } \\
\cline { 2 - 3 } & $\mathbf{n}$ & Tỹ lệ \% \\
\hline Thân trước & 123 & 96,09 \\
\hline ĐM thẹn & 1 & 0,78 \\
\hline ĐM bịt & 1 & 0,78 \\
\hline Thân sau & 3 & 2,34 \\
\hline Tống & $\mathbf{1 2 8}$ & $\mathbf{1 0 0}$ \\
\hline
\end{tabular}

Nhận xét: Động mạch mông dưới 96,09\% tách ra từ thân trước, $2,34 \%$ tách ra từ thân sau. Ngoài ra động mạch mông dưới còn tách ra từ động mạch thẹn, động mạch bịt với tỷ lệ 0,78\%.

3.6. Các biển đổi nguyên ủy động mạch

\section{tử cung}

Bảng 3.6. Các dạng biến đổi nguyên ủy động mạch tứ cung

\begin{tabular}{|c|c|c|}
\hline \multirow{2}{*}{ Từ Nguyên ủy } & \multicolumn{2}{|c|}{ Động mạch tử cung } \\
\cline { 2 - 3 } & $\mathbf{n}$ & Tỷ lệ \% \\
\hline Thân trước & 39 & 88,64 \\
\hline Đô̂ng mạch thẹn & 3 & 6,82 \\
\hline ĐM bàng quang giữa & 1 & 2,27 \\
\hline Động mạch bịt & 1 & 2,27 \\
\hline Tống & $\mathbf{4 4}$ & $\mathbf{1 0 0}$ \\
\hline
\end{tabular}

Nhận xét: Động mạch tử cung, 88,64\% là nhánh bên của thân trước động mạch chậu trong. 6,82\% động mạch tử cung được tách cùng động mạch thẹn tạo nên một thân chung, có thể tách cùng động mạch bàng quang giữa, động mạch bịt với tỷ lệ 2,27\%.

\subsection{Các biến đổi nguyên ủy đônng mạch bịt}

Bảng 3.7. Các dạng biến đổi nguyên üy động mạch bịt

\begin{tabular}{|c|c|c|}
\hline \multirow{2}{*}{ Từ Nguyên ủy } & \multicolumn{2}{|c|}{ Động mạch bịt } \\
\cline { 2 - 3 } & $\mathbf{n}$ & Ty̆ lệ $\%$ \\
\hline Thân trước & 105 & 91,30 \\
\hline ĐM thẹn & 4 & 3,48 \\
\hline Sinh dục & 4 & 3,48 \\
\hline Thượng vị dưới & 1 & 0,87 \\
\hline Thân sau & 1 & 0,87 \\
\hline Tống & $\mathbf{1 1 5}$ & $\mathbf{1 0 0}$ \\
\hline
\end{tabular}

Nhận xét: Động mạch bịt phần lớn là nhánh bên của thân trước động mạch chậu trong ở 91,30\%, 3,48\% động mạch bịt tách trực tiếp từ động mạch thẹn, 3,48\% tách trực tiếp từ động mạch sinh dục. Ngoài ra động mạch bịt có thể được tách ra từ động mạch thượng vị dưới và thân sau với tỷ lệ 2,27\%. 
3.8. Phân loại nguyên ủy động mạch mông trên, mông dưới và động mạch thẹn theo Adachy [3].

Bảng 3.8. Phân loại nguyên ửy động mạch mông trên, mông dưới và động mạch thẹn

\begin{tabular}{|c|c|c|c|}
\hline \multirow{2}{*}{ Phân loại Các biến thể } & \multirow{2}{*}{$\begin{array}{c}\text { Sự kết hợp giữa các } \\
\text { nhánh mạch }\end{array}$} & \multicolumn{2}{|c|}{ Các biến thể } \\
\hline & & $n$ & Tỷ lệ \% \\
\hline Loại I & $\begin{array}{c}\text { Động mạch mông dưới và động mạch thẹn } \\
\text { tách cùng thân }\end{array}$ & 16 & 13,79 \\
\hline Loại II & $\begin{array}{c}\text { Động mạch mông trên và động mạch mông } \\
\text { dưới tách cùng thân }\end{array}$ & 11 & 9,49 \\
\hline Loại III & $\begin{array}{l}\text { Động mạch mông trên, dưới và động mạch } \\
\text { thẹn tách trực tiếp từ ĐM chậu }\end{array}$ & 2 & 1,72 \\
\hline Loại IV & $\begin{array}{l}\text { Động mạch mông trên, dưới và động mạch } \\
\text { thẹn tách ra từ một thân chung }\end{array}$ & 1 & 0,86 \\
\hline
\end{tabular}

Nhận xét: Động mạch mông dưới và động mạch thẹn được tách cùng một thân gặp trong 13,79\%, khoảng 9,49\% động mạch mông trên và động mạch mông dưới tách ra cùng một thân, động mạch mông dưới và động mạch thẹn tách cùng thân trong $1,72 \%$ số trường hợp. Có $0,86 \%$ cả động mạch mông trên, mông dưới và động mạch thẹn tách ra từ một thân chung. Với cách phân loại này đã thuận tiện cho việc định danh và lập kế hoạch can thiệp các bệnh lý vùng chậu hông.

\section{BÀN LUÂ̂N}

Theo kết quả Bảng 3.1 chúng tôi nhận thấy, hầu hết nhóm bệnh nhân vào chụp vùng chậu bụng đều có độ tuổi trên 19 tuổi. Điều này có thể là do nhóm nam giới có nhiều yễu tố nguy cơ về bệnh lý tuyến tiền liệt và đại tràng, nữ giới thì cho thấy tỷ lệ giữa hai nhóm này là tương đương, từ 19 tuối đến 60 tuổi là $43 \%$, trên 60 tuổi là $53,56 \%$; điều này có thể do phụ nữ ngay từ khi trên 19 tuổi đã liên quan nhiêu đến các bệnh lý phụ khoa.

Khi tiến hành khảo sát đường kính các đoan động mạch chậu trong và các nhánh cho thẩy, đoạn động mạch chậu chung, thân trước và thân sau có đường kính từ $3 \mathrm{~mm}$ đến $4 \mathrm{~mm}$, trong khi các nhánh mạch có đường kính từ $1 \mathrm{~mm}$ đến $2 \mathrm{~mm}$. Kết quả nghiên cứu của chúng tôi cũng tương đồng với nghiên cứu của Linli (B)[5] Satheesha Badagabettu Nayak(C). Với đường kính của các nhánh mạch chính có thể sử dụng để đặt stent lòng mạch trong khi hẹp tắc, nhưng sẽ là khó khăn cho thủ thuật nút mạch cầm máu. Ngược lại các nhánh nhỏ lại khó thực hiện đặt stent thì có thể nút mạch khi xuất huyết hay khi cần điều trị khối u.

Sự biến đổi các nhánh mạch từ động mạch chậu là rất phong phú. Động mạch mông trên, động mạch mông dưới, động mạch tử cung hay động mạch bịt đều có nhiều vị trí nguyên ủy khác nhau (Bảng 3.3 đến Bảng 3.7). Kết quả nghiên cứu của chúng tôi cũng tương đồng với số liệu nghiên cứu của Faredine Fade, Fabienne Gobel và CS (2013)[3]. Sự biến đổi nguyên ủy của các nhánh mạch làm thay đổi nguồn cấp máu cho các tạng, đây là một thách thức cho các nhà ngoại khoa hay các nhà can thiệp mạch. Nếu không kiểm soát tốt nguồn gốc các nhánh mạch có thể can thiêp nhầm đông mach, dẫn đến hoạ tử các tạng. Mặt khác, nếu nút mạch cầm máu mà lại bỏ sót các nhánh mạch từ nguồn mạch khác đến thì gây chẩy máu. Sự biến đổi của đông mach tử cung còn được khẳng định bởi Moses M. và cộng sự [7], 46,2\% số trường hợp nghiên cứu có nguyển ủy khác so với các mô tả trong sách giải phẫu kinh điển. Chính điều này đã gây khó khăn cho các nhà can thiệp mạch để tìm vị trí nguyên ủy, dẫn tới tăng thời gian can thiệp và tăng thuốc cản quang. Để hạn chế điều này thì các phim chụp cắt lớp vi tính tỏ ra vượt trội và giải quyết triệt để khó khăn này, ít tai biến.

Với sự biến đổi về nguyên ủy của động mạch bịt đã gây nhiều khó khăn cho các nhà lâm sàng, khi thực hiên các thủ thuât vùng chậu hông và các tổn thương đáy ổ cối. Thực tế động mạch này lại ít được các tác giả đưa vào để phân loại các biến đổi của động mạch vùng chậu (Bảng 3.8). Điều này có thể là do động mạch bịt chủ yếu nuôi dưỡng cho các cấu trúc về cớ, da mà hiếm khi cho các nhánh mạch vào tuyến tiền liệt, trực tràng hay tử cung, bởi vậy ít được chú ý mô tả trong các thủ thuật can thiệp.

\section{KẾT LUÂ̂N}

5.1 Kích thước: Đường kính đoạn động mạch chậu chung, thân trước và thân sau khoảng $3 \mathrm{~mm}$. Các nhánh mạch tách ra từ thân này đều nhỏ hơn $2 \mathrm{~mm}$. Với đường kính của các nhánh mạch là thuận lợi cho việc đặt stent và điều trị nút mạch.

5.2 Các biến đổi giải phẫu: $0,78-6,82 \%$ 
các trường hợp có biến đổi nguyên ủy các nhánh mạch, điều này là một thách thức cho các nhà can thiệp mạch, cũng như phẫu thuật các tạng vùng chậu khi chảy máu.

\section{KIẾN NGH!}

Đây là kỹ thuật tạo ảnh nhanh, đơn giản, không xâm lấn, cho kết quả chính xác và có ý nghĩa thực tiễn cao do đó cần khảo sát các mạch này trên MSCT trước khi can thiệp mạch.

\section{TÀl LIẸU THAM KHẢO}

1. Đào Danh Vĩnh, Phạm Minh Thông (2012). "Kết quả ban đâu can thiệp nội mạch trong tái thông hẹp tắc động mạch chậu". Điện quang Việt Nam số 8, tr. 269-275

2. Nguyễn Văn Thanh, Nguyễn Văn Huê, Trân Vần Anh. (2016). nghiên cứu giải phẫu nhánh xuyên động mạch mông trên. ứng dụng trong tạo vạt da cân vùng mông có cuống nuôi. Tạp chí Y
Dược học Quân sự sỗ 9

3. Adachy B, Das Arteriensystem der japaner, Bd. H.Kyoto. (1928). Supp. To Acta Scholae Medicinalis Universitatis Imperalis in Kiota. 1926-27.

4. Farrer-Brown G, Beilby JOW, Tarbit MH. (1970). The blood supply to the uterus: Arterial vasculature. Obstet Commonw. 1970;8: 673-681.

Gynaecol

5. Lin li, ketong wu, yang liu. et . al . (2019) Angiographic evaluation of the internal iliac artery branch in pelvic tumour patients: Diagnostic performance of multislice computed tomography angiography. ONCOLOGY LETTERS 17: 4305-4312

6. Mangala M. Pai. et. al, (2009), variability in the origin of the obturatorartery clinics, 64(9):897-901.

7. Moore KL. (1992). Clinically oriented anatomy, 4th ed., Baltimore, U.S.A; p.350-55.

8. Pelage JP, Le Dref O, Soyer $\mathbf{P}$, et al. (1999). Arterial anatomy of the female genital tract: variations and relevance to transcatheter embolization of the uterus. AJR Am J Roentgenol. 1989-994.

\section{NGHIÊN CỨU THƯC TRANG VÀ MộT SỐ YẾU TỐ ẢNH HƯỞNG TỚI CÔNG VIÊCC CỦA ĐIỂU DƯỡNG TẠI 5 TRUNG TÂM Y TẾ TUYẾN HUYÊ̂N VÀ BÊ̂NH VIÊ̂N KHU VỰC TỈNH BÌNH ĐİNH NĂM 2020}

\section{TÓM TẮT}

Kết quả nghiên cứu cho thây 3 đơn vị cho rằng khối lượng công viêc là vứa, 2 đơn vị là nhiêuu., Nhiệt độ không khí tại nới làm việc được các ĐDV đánh giá là nóng quá chiếm tỉ lệ cao.TTYT Hoài Ân 84\%; TTYT huyện Tây Sơn chiếm 73,5\%; TTYT huyện Phù Mỹ chiếm $73,2 \%$ và BV đa khoa Bồng Sơn chiếm $64,8 \%$. Tiếng ồn: Cao nhất là TTYT huyện Tây Sơn 100\%; kế tiếp là BV đa khoa Bồng Sơn 80,3ั\%; TTYT huyện Hoài Ân là 72\%; TTYT huyện Hoài Ân 72\%; TTYT huyện Phù Mỹ $58,5 \%$ và TTY' TP Quy Nhơn là $41,7 \%$. Tỉ lệ tiếp xúc với bụi tại nơi làm việc cao nhất là TTYT huyện Tây Sơn 85,3\%, tiếp theo là BV đa khoa Bồng Sơn t $81,7 \%$. Thấp nhất là TTYT TP Quy Nhơn với 13,9\%. Tỉ lệ tiếp xúc với hơi, khí độc, hoá chất tại TTYT huyên Hoài Ân là cao nhất tỉ lệ $36 \%$, thấp nhất là BV đa khoa Bồng Sơn chiếm $11,3 \%$. Về sự lây nhiễm HIV các ĐDV lo lắng/căng thẳng chiếm tỉ lệ cao nhất với $32,9 \%$; sự lây nhiễm các bệnh truyền nhiễm khác 33,3\%; áp lực trước các thông tin về công việc hằng ngày trên các phương tiện thông tin $36,7 \%$; thái đồ, phản ứng, thắc mắc của bệnh nhân, người nhà bệnh nhân các ĐDV cho rằng bình thường với tỉ lệ là $36,2 \%$. Khuyến nghị: Cần có giải pháp cải thiện các

*Trường Đại hoc Quang Trung

Chịu trách nhiệm chính: nguyền Huy Nga

Email: huynga2000@gmail.com

Ngày nhận bài: $1 / 6 / 2021$

Ngày phản biên khoa học: 29/6/2021

Ngày duyệt bài: 15/7/2021
Lê Văn Tàu*, Nguyễn Huy Nga*, Mai Tường Vy*

điều kiện của môi trường làm việc cho điều dưỡng viên,

Tư khóa: Gánh nặng lao động ĐDV, trung tâm y tế, tỉnh Bình Định

\section{SUMMARY}

LABOR BUDEN OF NURSES AND SOME
FACTORS AFECTING AT 5 DISTRICT
HEALTH CENTERS AND AERA HOSPITAL HEALTH CENTERS AND AERA HOSPI
IN BINH DINH PROVINCE

The research results show that 3 units have moderate workload, while the Phu My district health center $(51.2 \%)$ and Tay Son district health center $(50 \%)$ think that the workload is too much.. Hot environment: Hoai An DHC 84\%; Tay Son DHC 73.5\%; Phu My DHC 73.2\% and Bong Son general hospital $64.8 \%$. Noise: the highest is Tay Son DHC $100 \%$; Bong Son G H 80.3\%; Hoai An DHC 72\%; Phu My DHC $58.5 \%$ and tQuy Nhon city HC $41.7 \%$. The highest rate of exposure to dust at work is the Tay Son DHC at $85.3 \%$, Bong Son GH of $81.7 \%$. Quy Nhon City HC $13.9 \%$. The rate of exposure to toxic vapors, gases and chemicals at the Hoai An DHC í $36 \%$, Bong Son GH is 11.3 . Regarding HIV infection risk, nurses worried/being stressed accounted 32.9\%; the spread of other infectious diseases 33.3\%; pressure from information about daily work on the media $36.7 \%$; Attitudes, reactions, questions of patients, patients' family nurses think normal with the rate of $36.2 \%$. Recommendation: It is necessary to have solutions to improve the conditions of the working environment for nurses. 